\title{
Blunted $\gamma \delta$ T-lymphocyte response in chronic obstructive pulmonary disease
}

\author{
J. Pons*,\#, J. Sauleda", J.M. Ferrer", B. Barceló ${ }^{+}$, A. Fuster ${ }^{\#}$, V. Regueiro*, \\ M.R. Julià ${ }^{\#}$ and A.G.N. Agustí*,
}

ABSTRACT: Chronic obstructive pulmonary disease (COPD) is characterised by an excessive inflammatory response to inhaled particles, mostly tobacco smoking. Although inflammation is present in all smokers, only a percentage of them develop COPD. T-lymphocytes are important effector and regulatory cells that participate actively in the inflammatory response of COPD. They comprise the T-cell receptor (TCR)- $\alpha \beta$ (CD4+ and CD8+) and TCR- $\gamma \delta$ T-lymphocytes. The latter represent a small percentage of the total T-cell population, but play a key role in tissue repair and mucosal homeostasis.

To investigate TCR- $\alpha \beta$ (CD4+ and CD8+) and TCR- $\gamma \delta$ T-lymphocytes in COPD, the present authors determined, by flow cytometry, the distribution of both subpopulations in peripheral blood and bronchoalveolar lavage (BAL) samples obtained from patients with COPD, smokers with normal lung function and never-smokers.

The present study found that: 1) the distribution of CD4+ and CD8+ lymphocytes in blood and BAL was similar in all three groups; 2) compared with nonsmokers, $\gamma \delta$ T-lymphocytes were significantly increased in smokers with preserved lung function; and 3) this response was blunted in patients with COPD.

These results highlight a novel, potentially relevant, pathogenic mechanism in chronic obstructive pulmonary disease.

KEYWORDS: Flow cytometry, lung inflammation, mucosal homeostasis, tissue repair

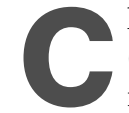
hronic obstructive pulmonary disease (COPD) is characterised by a marked inflammatory response of the airways and lung parenchyma to inhaled particles, mostly tobacco smoking [1]. Inflammation is usually present in the lungs of smokers, but, for reasons that are still poorly understood, only a percentage of them develop airflow limitation [2].

T-lymphocytes are key inflammatory effector and regulatory cells that participate in the inflammatory response of COPD [3]. On their cell surface, T-lymphocytes express the T cell receptor (TCR), which recognises peptides in the groove of the major histocompatibility complex of antigenpresenting cells, and the CD3 complex, which initiates intracellular signal transduction pathways [4]. T-cells are classified as TCR- $\alpha \beta$ and TCR $-\gamma \delta$ according to the TCR expressed. The former comprise $\sim 95 \%$ of the T-cell population and can be subdivided in two main subpopulations including: 1) CD4+ T-lymphocytes, which, under normal conditions comprise $60-70 \%$ of the total TCR- $\alpha \beta$ population and are cytokinesecreting helper cells, and 2) CD8+T-lymphocytes, which represent $30-40 \%$ of it and are cytotoxic killer cells. In contrast, TCR- $\gamma \delta$ lymphocytes account for only $\sim 5 \%$ of the total T-cell subpopulation. However, they play a key role in mucosal homeostasis and the reparative response to tissue damage [5]. Furthermore, those $\gamma \delta$ T-cells that coexpress the CD8 receptor have marked anti-inflammatory effects and contribute to suppress the cell-mediated immune response [6].

Previous studies have reported increased numbers of T-lymphocytes in the lung parenchyma and bronchial tissue of patients with COPD, predominantly CD8+ (thus with a low CD4+:CD8+ ratio) [7-9]. In contrast, much less is known about the role of $\gamma \delta$ T-lymphocytes in COPD. However, given their important role in epithelial repair [10], it is possible that abnormalities in their regulation can contribute to the pathogenesis of the disease. Further, whether abnormalities in T-lymphocyte distribution represent a local inflammatory event or reflect a systemic abnormality is unclear [11], but it is worth noting that the $\mathrm{CD} 4+\mathrm{CD} 8+$ ratio of circulating lymphocytes appears to be genetically determined [12]. Thus, it is possible that the lungs
AFFILIATIONS

*Unidad de Investigación,

\#Inmunología,

"Neumología, and

+Análisis Clinicos, Hospital

Universitario Son Dureta, Institut

Universitari d'Investigació en

Ciències de la Salut (IUNICS), Palma

de Mallorca, Spain.

CORRESPONDENCE

A.G.N. Agustí

Servei de Pneumologia

Hospital Universitari Son Dureta

Andrea Doria 55

07014- Palma de Mallorca

Spain

Fax: 34971175228

E-mail: aagusti@hsd.es

Received:

June 102004

Accepted after revision:

November 282004 
of smokers with intrinsically low CD4+:CD8+ ratios are more susceptible to the damaging effects of smoking. COSTABEL et al. [13] previously investigated this question in bronchoalveolar lavage (BAL) and peripheral blood samples of smokers (with and without chronic mucous production) and nonsmokers. Unfortunately, however, COPD smokers were not studied.

To better characterise the percentage of the different $\mathrm{T}$ lymphocyte subpopulations in the inflammatory process that underlies COPD, the present study sought to compare the distribution of circulating and pulmonary TCR $-\alpha \beta$ and TCR- $\gamma \delta$ T-lymphocytes in COPD patients, smokers with normal lung function and nonsmokers.

\section{METHODS}

\section{Population and ethics}

All participants required bronchoscopy for the clinical evaluation of a solitary pulmonary nodule or haemoptysis, and gave their written consent after being fully informed of the nature, characteristics, risks and potential benefits of the study, which was previously approved by the local ethics committee, Hospital Son Dureta, Palma de Mallorca, Spain. COPD patients were clinically stable and had not had an exacerbation during the last 3 months. All of them were being treated with inhaled bronchodilators. Six patients also received inhaled steroids, but none was on oral steroid therapy. Subjects with atopic diseases, allergic rhinitis and asthma were excluded. To avoid any potential effect of acute smoking, active smokers refrained from smoking $12 \mathrm{~h}$ before bronchoscopy. Exhaled carbon monoxide concentration was $<10$ parts per million in all subjects.

\section{Lung function}

Forced spirometry (Gold standard; Warren E. Collins, Braintree, MA, USA) was obtained in all participants [14]. Spirometric reference values were those of a Mediterranean population [15].

\section{Bronchoalveolar lavage fluid and blood samples}

Bronchoscopy was performed with a flexible fibreoptic bronchoscope (Pentax 15v; Pentax, Tokyo, Japan). Under topical lidocaine, BAL was performed by instilling eight 25$\mathrm{mL}$ aliquots of sterile saline solution in one pulmonary segment of a lower lobe without any lung nodules. The liquid recovered was filtered, washed twice in PBS and resuspended at $10^{6}$ cells $\cdot \mathrm{mL}^{-1}$ in RPMI- 1640 medium at $4{ }^{\circ} \mathrm{C}$. Blood samples were collected before bronchoscopy by peripheral venipuncture.

\section{Flow cytometry}

BAL and blood samples were incubated with a combination of anti-CD4 fluorescein isothiocyanate (FITC), anti-CD8 Phycoerythrin (PE) and anti-CD3 Phycoerythrin-Cyanin 5 (PC5) or anti-CD8 FITC, anti-TCR- $\gamma \delta$ PE and anti-CD3 PC5 conjugated monoclonal antibodies (Coulter Immunotech, Izasa, Spain) for $15 \mathrm{~min}$ at room temperature in the dark. Then, $2 \mathrm{~mL}$ of lysing solution (Becton Dickinson, Madrid, Spain) was added, and cells were washed and resuspended in PBS. The analysis was carried out in an Epics XL flow cytometer using the Expo32 software (Coulter Immunotech). The percentage of $\mathrm{CD} 4+, \mathrm{CD} 8+, \gamma \delta$ and $\gamma \delta \mathrm{CD} 8+$ was referred to as the total amount of T-lymphocytes (CD3+ cells) gating on a side versus the CD3 dot plot.

\section{Statistical analysis}

One-way ANOVA with Bonferroni contrasts was used to compare differences between groups. A p-value $<0.05$ was considered statistically significant.

\section{RESULTS}

\section{Clinical and functional findings}

Table 1 shows the main clinical and functional characteristics of the three groups studied. COPD patients were slightly older than the other two groups. The smoking history of patients with COPD and smokers with normal lung function was similar. Patients with COPD showed moderate airflow obstruction, whereas spirometry was normal in the other two groups.

\section{Circulating and pulmonary $\alpha \beta$ T-lymphocytes}

In blood, the percentage of CD4+ $(60.0 \pm 4.7,57.1 \pm 2.7$ and $60.2 \pm 3.1 \%$; fig. 1a) or CD8+ T-lymphocytes (35.6 \pm 4.6 , $35.2 \pm 2.6$ and $34.6 \pm 3.0 \%$; fig. $1 b$ ) was similar in COPD patients, smokers with normal lung function and never smokers, respectively. In BAL, the present authors observed a trend towards lower levels of CD4+ T-cells in smokers (with or without COPD; $50.6 \pm 3.5$ and $50.7 \pm 4.3$, respectively) than in nonsmokers $(65.2 \pm 4.9 \%$; fig. 1c), and a corresponding trend towards higher CD8+ T-cell values in COPD patients and smokers with normal lung function $(42.5 \pm 2.9$ and $41.2 \pm 4.6 \%$, respectively) than in nonsmokers $(30.9 \pm 4.7 \%$; fig. $1 \mathrm{~d})$. However, none of these differences reached statistical significance.

\section{Circulating and pulmonary $\gamma \delta$ T-lymphocytes}

The percentage of circulating $\gamma \delta$ T-lymphocytes was higher in smokers with normal lung function $(5.0 \pm 0.8 \%)$ than in nonsmokers $(3.2 \pm 0.8 \%)$ or COPD patients $(2.4 \pm 0.4 \%$, $\mathrm{p}<0.05$; fig. 2a). In contrast, double positive $\gamma \delta \mathrm{CD} 8+$ were not different $(p=0.2)$ between groups (fig. $2 b)$. In BAL, smokers with normal lung function also showed a significant upregulation of $\gamma \delta$ T-lymphocytes compared with nonsmokers $(8.2 \pm 1.0$ versus $1.4 \pm 0.3 \%$, $\mathrm{p}<0.001$; fig. $2 \mathrm{c})$. Interestingly, this response was blunted in COPD patients $(3.6 \pm 0.6 \%, \mathrm{p}<0.001)$. The $\gamma \delta$ CD8+ double positive subpopulation was also higher in

\begin{tabular}{|c|c|c|c|}
\hline & Never-smokers & Smokers $\#$ & COPD \\
\hline Subjects $n$ & 10 & 20 & 20 \\
\hline Age yrs & $57.8 \pm 6.3$ & $58.0 \pm 1.9$ & $66.4 \pm 1.6$ \\
\hline $\begin{array}{l}\text { Smoking history } \\
\text { pack-yrs }\end{array}$ & 0 & $41.1 \pm 3.2$ & $52.1 \pm 4.7$ \\
\hline FEV $_{1} \%$ pred & $95.8 \pm 5.1$ & $91.3 \pm 2.5$ & $55.4 \pm 3.0^{+}$ \\
\hline FEV1/FVC \% & $81.8 \pm 2.5$ & $77.0 \pm 1.7$ & $52.5 \pm 2.1^{+}$ \\
\hline \multicolumn{4}{|c|}{$\begin{array}{l}\text { Data are presented as } n \text { and mean } \pm \mathrm{SD} \text {. COPD: chronic obstructive pulmonary } \\
\text { disease; FEV1: forced expiratory volume in one second; FVC: forced vital } \\
\text { capacity. }{ }^{\#} \text { : with normal lung function; }{ }^{\imath}: \mathrm{p}<0.05 \text { COPD versus smokers with } \\
\text { normal lung function; }{ }^{+}: \mathrm{p}<0.0001 \text { COPD versus smokers with normal lung } \\
\text { function and nonsmokers. }\end{array}$} \\
\hline
\end{tabular}



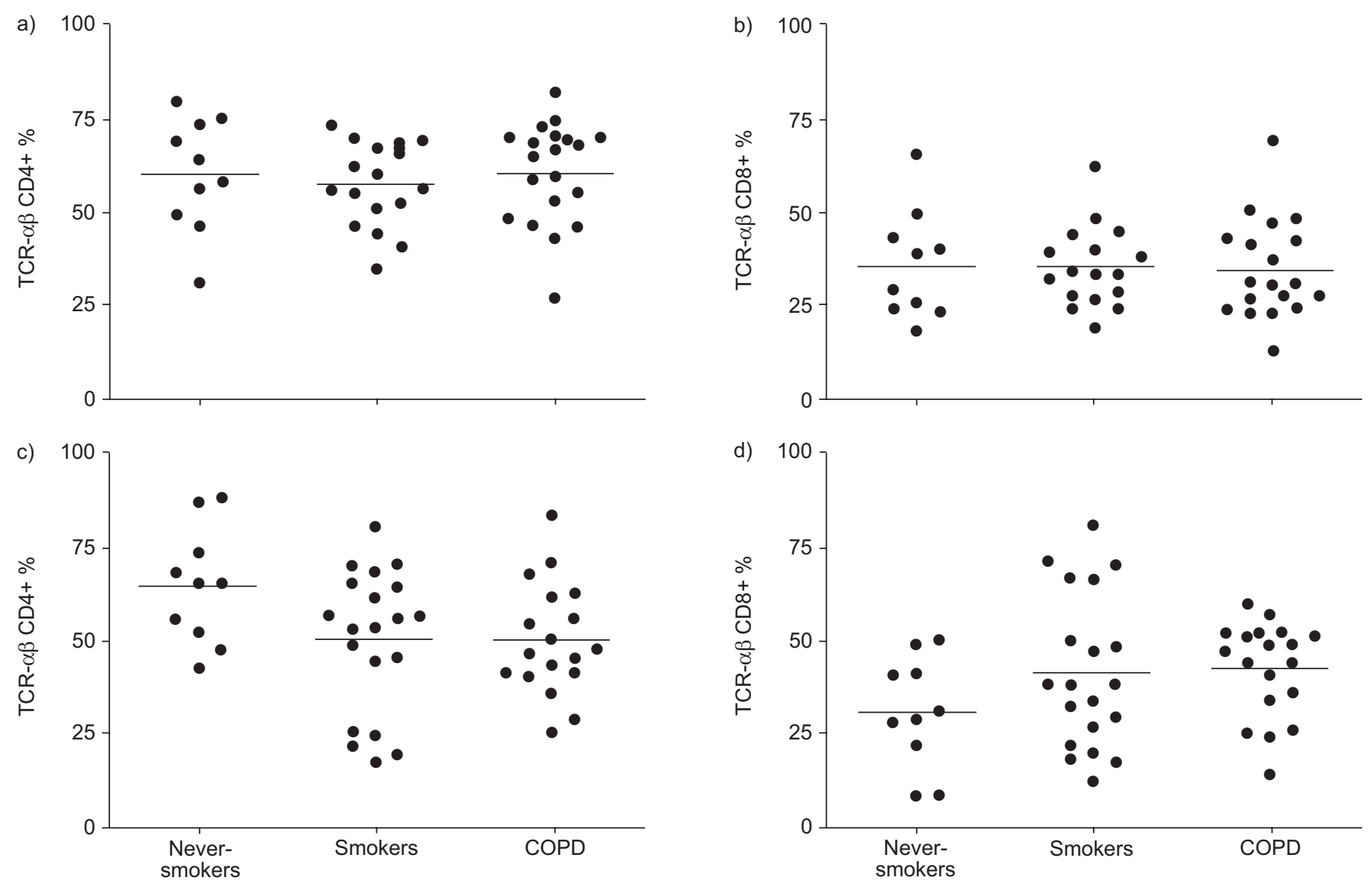

FIGURE 1. Percentage of T-cell receptor (TCR)- $\alpha \beta$ CD4+ and CD8+ T-lymphocytes in peripheral blood (a and b) and bronchoalveolar lavage samples (c and d) in neversmokers, smokers with normal lung function and chronic obstructive pulmonary disease (COPD) patients. Horizontal bars represent the mean value. Differences between groups did not reach statistical significance.

smokers with normal lung function $(3.6 \pm 0.8 \%)$ than in COPD patients $(0.4 \pm 0.1 \%, \mathrm{p}<0.001)$ or nonsmokers $(0.5 \pm 0.2 \%$, $\mathrm{p}<0.01$; fig. $2 \mathrm{~d}$ ). These results were unchanged if COPD patients receiving treatment with inhaled steroids $(n=6)$ were excluded from the analysis (data not shown).

Figure $3 \mathrm{a}$ shows the percentage of pulmonary $\gamma \delta$ T-cells in patients with COPD and in smokers with normal lung function, grouped according to their smoking status (current versus ex-smokers). Current smokers with normal lung function showed a significant upregulation of $\gamma \delta$ T-cells when compared with ex-smokers with normal lung function $(10.5 \pm 0.9$ versus $5.4 \pm 1.6$, respectively; $\mathrm{p}<0.01)$. This suggests that active smoking induces a physiological response characterised by upregulation of pulmonary $\gamma \delta$ T-lymphocytes. Interestingly, this response was blunted in current smokers with COPD $(3.2 \pm 1.2 \%, \mathrm{p}<0.001)$. Similar results were found when the $\gamma \delta$ CD8+ subpopulation was evaluated (fig. 3b), their percentage being higher in current smokers with normal lung function $(5.3 \pm 1.1 \%)$ than in ex-smokers with normal lung function $(1.3 \pm 0.4, \mathrm{p}<0.001)$ or current smokers with COPD $(0.5 \pm 0.2, \mathrm{p}<0.001)$.

\section{DISCUSSION}

The present study investigated potential abnormalities in the distribution of different subpopulations of T-lymphocytes in peripheral blood and BAL samples in patients with COPD, as compared with smokers with normal lung function and never-smokers. The current authors did not find any significant differences in the distribution of $\alpha \beta$ T-lymphocytes (CD4+ or CD8+) between groups, either in peripheral blood or BAL samples (fig. 1). In contrast, a very significant upregulation of $\gamma \delta$ T-lymphocytes in smokers with preserved lung function (both in peripheral blood and, particularly, in BAL samples) was observed (fig. 2). The fact that this response was remarkably diminished in smokers with COPD, given the important role of $\gamma \delta$ T-lymphocytes in tissue repair and inflammation control, identifies a novel, potentially relevant mechanism of the disease.

\section{$\alpha \beta$ T-lymphocytes}

Previous studies have reported increased percentages of CD8+ T-lymphocytes in peripheral [8] and central airways [9], as well as in the lung parenchyma and pulmonary vasculature [7] of COPD patients. In BAL, the present authors did not find significant differences in the distribution of CD8+ T-lymphocytes between COPD patients, smokers with normal lung function and never smokers, albeit smokers (with and without COPD) showed a tendency towards higher CD8+ values (fig. 1d). Differences with respect to previous studies [7-9] may relate to different sampling sites. For instance, it is well known that the concentration of neutrophils is increased in 

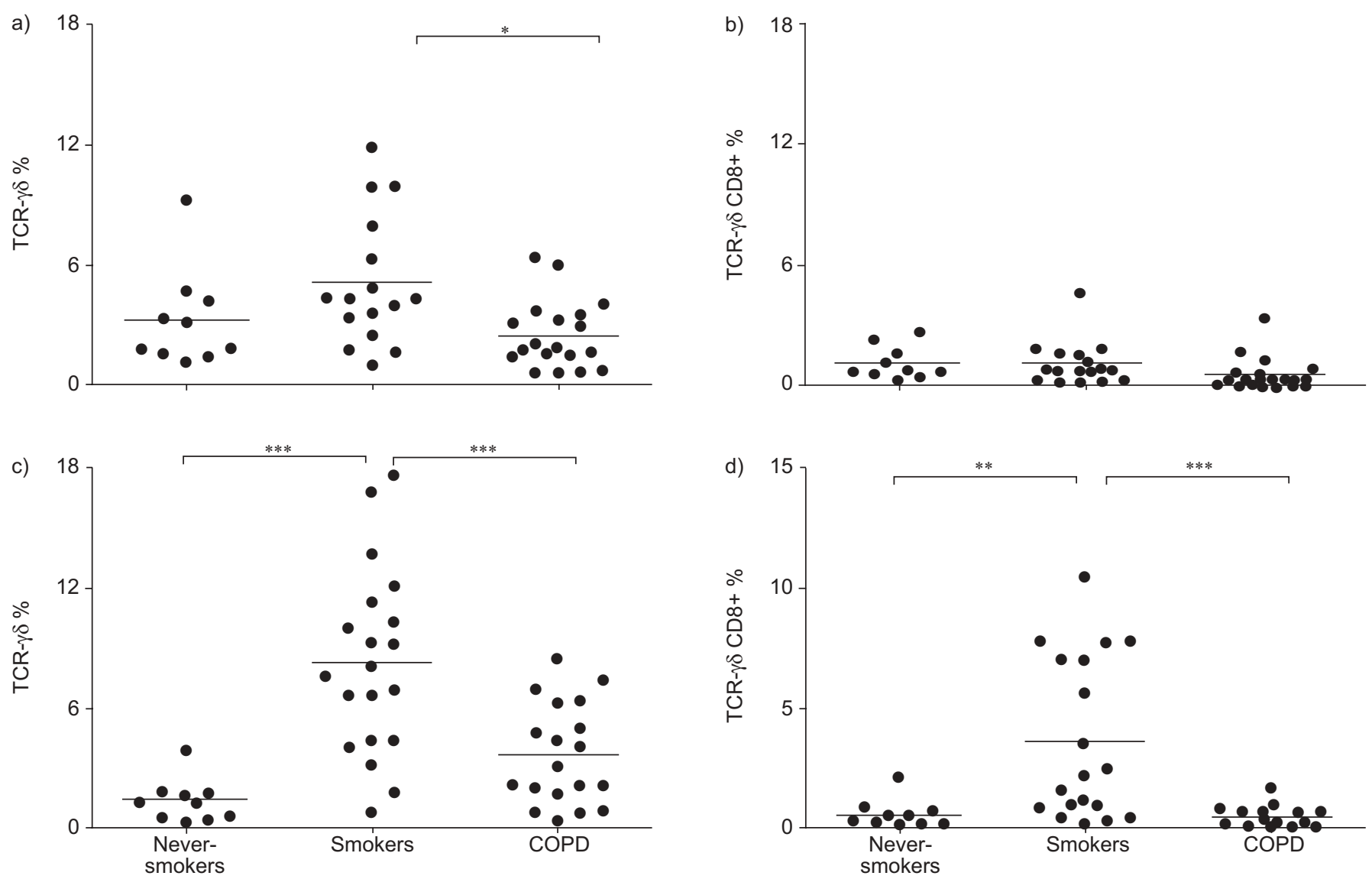

FIGURE 2. Percentage of T-cell receptor (TCR)- $\gamma \delta$ and $-\gamma \delta$ CD8+ T-lymphocytes in peripheral blood $(a$ and $b)$ and bronchoalveolar lavage samples (c and d) in neversmokers, smokers with normal lung function and chronic obstructive pulmonary disease (COPD) patients. Horizontal bars represent the mean value. ${ }^{*}: p<0.05 ;{ }^{*}$ : $p<0.01$; $\star * *: p<0.001$. Where not indicated, differences between groups were not statistically significant.

BAL samples of patients with COPD, whilst they are found only rarely in tissue samples [16].

Only a few studies have investigated the distribution of CD4+ and CD8+ T-lymphocytes in the peripheral blood of COPD patients. DE JONG et al. [17] found no differences between smokers with or without COPD. More recently, KIM et al. [18] also found similar percentages of CD8+ T-cells in COPD patients and healthy smokers. The presented results agree with these two previous studies (figs 1a and c), suggesting that the origin of the abnormal T-lymphocyte infiltration seen in the lungs of patients with COPD is a local rather than a systemic event.

\section{$\gamma \delta$ T-lymphocytes}

$\gamma \delta$ T-lymphocytes play an important role in tissue repair and mucosal homeostasis [5]. Little is known about their potential role in COPD, except that they are an important component of tissue injury and remodelling [19]. A previous study by RICHMOND et al. [20] reported increased $\gamma \delta$ T-cell numbers in the bronchial glands of smokers compared with nonsmokers. Likewise MAJO et al. [21] found an increased percentage of $\gamma \delta$ T-lymphocytes in the lung parenchyma of smokers. Finally, EKBERG-JANSSON et al. [22] evaluated $\gamma \delta$ T-cells in peripheral blood and BAL samples, and also found a trend towards higher levels of $\gamma \delta$ T-cells in smokers with normal lung function. The present study confirms that, compared with never-smokers, smokers with normal lung function show a prominent upregulation of $\gamma \delta$ T-lymphocytes in peripheral blood and, particularly, in BAL. It also shows that this occurs only in active smokers (figs $3 a$ and $b$ ). Given the relevance of this T-lymphocyte subpopulation in tissue homeostasis, this observation is compatible with a physiological response aimed at protecting or repairing the lungs from the injury caused by current tobacco smoking. The specific molecular mechanisms leading to this upregulation of $\gamma \delta$ T-lymphocytes in smokers are unknown. The current authors speculate that a direct stimulatory effect of some component(s) of smoke and/or the presence of the so-called "danger signals" produced by the damaged lung parenchyma may contribute to it.

In contrast, the present study shows for the first time that COPD patients are unable to mount such a response (figs 2 and 3). This can have two important pathogenic implications. First, it can jeopardise their capacity to repair the lung parenchyma, as illustrated in $\gamma \delta$ T-lymphocytes knock-out mice that exhibit markedly delayed wound repair and re-epithelisation due to the deficient production of keratinocyte growth factors and other cytokines $[10,23,24]$. Secondly, it may facilitate the perpetuation of the inflammatory response [25, 26]. This is 

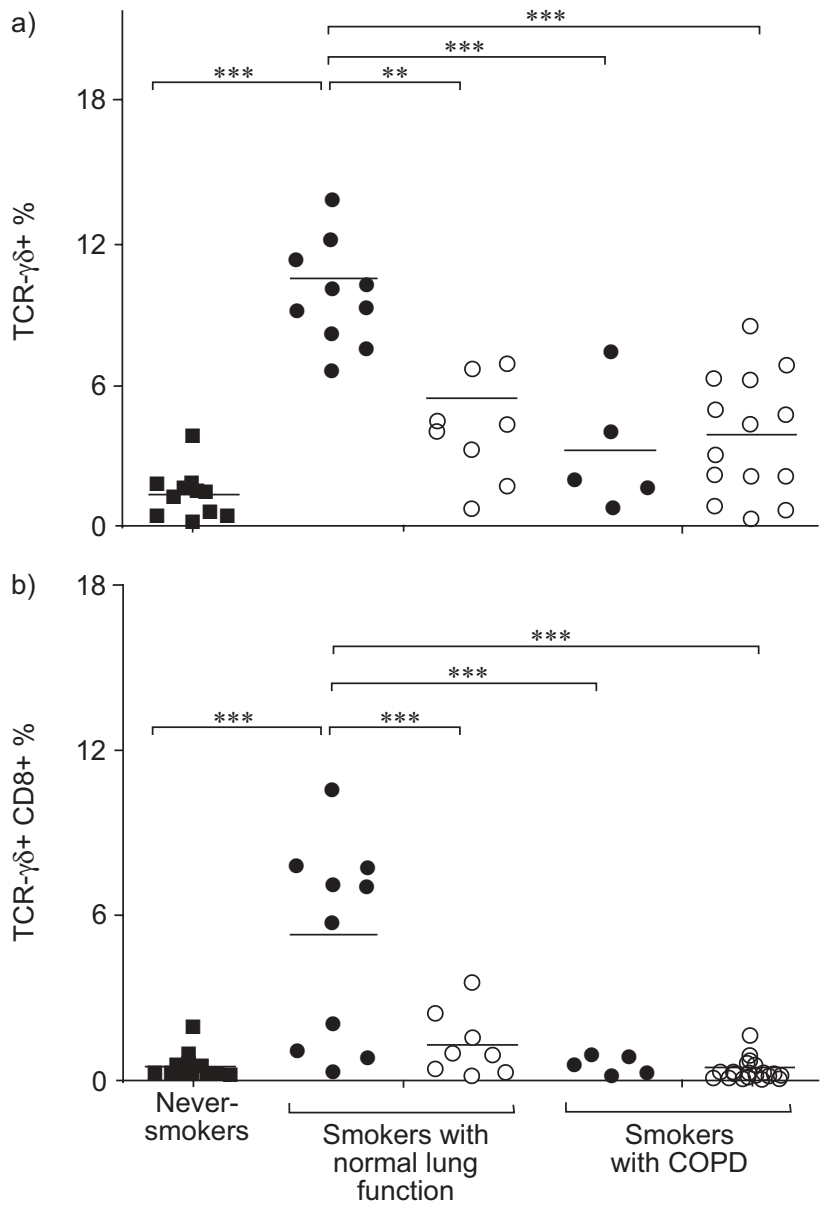

FIGURE 3. Percentage of T-cell receptor (TCR) $-\gamma \delta$ (a) and $-\gamma \delta$ CD8+ (b) T-cells in bronchoalveolar lavage fluid samples in never-smokers, current $(\bullet)$ and exsmokers $(\bigcirc)$ with normal lung function or chronic obstructive pulmonary disease (COPD) patients. Horizontal bars represent the mean value. ${ }^{* *}: p<0.01 ; * \star *$ : $p<0.001$. Where not indicated, differences between groups were not statistically significant.

particularly relevant for $\gamma \delta \mathrm{CD} 8+$ positive T-cells which, at variance with $\gamma \delta$ CD8- cells, can suppress the tissue damage mediated by effector T-cells [6].

Two potential limitations of the current study deserve some discussion. First, patients with COPD were slightly older than the other two groups (table 1). Previous studies have suggested that the number of circulating $\gamma \delta$ T-lymphocytes decreases with age $[27,28]$. No information is available on the effects of ageing on $\gamma \delta$ T-lymphocytes in the lungs. Therefore, the fact that patients with COPD were slightly older cannot be ignored and this may have influenced their results (fig. 2). However, it is believed that this factor is irrelevant for the comparison of never-smokers and smokers with normal lung function (fig. 2) because these two groups were well matched for age (table 1). Secondly, patients with COPD received pharmacological therapy, including steroids and bronchodilators. As discussed earlier, the former did not appear to influence the number of $\gamma \delta$ T-lymphocytes in these patients. In contrast, the potential effects of bronchodilators on these cells cannot be assessed because all patients in the study were receiving them and, to the best of the authors' knowledge, there is no information available in the literature regarding this specific point.

In summary, the present study found that current smokers with preserved lung function showed a prominent upregulation of $\gamma \delta$ and $\gamma \delta$ CD8+ T-lymphocytes in bronchoalveolar lavage fluid, and that this response was blunted in smokers who had developed chronic obstructive pulmonary disease. Whether this constitutes a previously unreported pathogenic factor that facilitates the development of chronic obstructive pulmonary disease among certain smokers or, alternatively, whether it is a consequence of the disease process that contributes towards amplification of the inflammatory response caused by smoking and/or this prevents effective tissue repair, although these theories cannot be ascertained from the presented results. However, in both instances, the results of the present study pinpoint a novel, potentially relevant mechanism of disease that deserves further investigation.

\section{ACKNOWLEDGEMENTS}

This study was supported, in part, by Fondo de Investigaciones Sanitarias (FIS 02/0986 and Red RespiraRTIC 03/11C), Sociedad Española de Patología del Aparato Respiratorio, Govern Balear and Asociació Balear per l'estudi de Malalties Respiratòries. The authors would like to thank C. Santos for her technical assistance.

\section{REFERENCES}

1 Jeffery PK. Structural and inflammatory changes in COPD: a comparison with asthma. Thorax 1998; 53: 129-136.

2 Fletcher C, Peto R. The natural history of chronic airflow obstruction. BMJ 1997; 1: 1645-1648.

3 Barnes PJ. Chronic obstructive pulmonary disease. N Engl J Med 2000; 343: 269-280.

4 Janeway CA. The $\mathrm{T}$ cell receptor as a multicomponent signalling machine: CD4/CD8 coreceptors and CD45 in T cell activation. Annu Rev Immunol 1992; 10: 645-674.

5 Jameson J, Witherden D, Havran WL. T-cell effector mechanisms: gammadelta and CD1d-restricted subsets. Curr Opin Immunol 2003; 15: 349-353.

6 Harrison LC, Dempsey-Collier M, Kramer DR, Takahashi K. Aerosol insulin induces regulatory CD8 gamma delta $\mathrm{T}$ cells that prevent murine insulindependent diabetes. J Exp Med 1996; 184: 2167-2174.

7 Saetta M, Baraldo S, Corbino L, et al. CD8+ve cells in the lungs of smokers with chronic obstructive pulmonary disease. Am J Respir Crit Care Med 1999; 160: 711-717.

8 Saetta M, Di Stefano A, Turato G, et al. CD8+ Tlymphocytes in peripheral airways of smokers with chronic obstructive pulmonary disease. Am J Respir Crit Care Med 1998; 157: 822-826.

9 O'Shaughnessy TC, Ansari TW, Barnes NC, Jeffery PK. Inflammation in bronchial biopsies of subjects with chronic bronchitis: inverse relationship of CD8+ T lymphocytes with FEV1. Am J Respir Crit Care Med 1997; 155: 852-857.

10 Jameson J, Ugarte K, Chen N, et al. A role for skin gammadelta T cells in wound repair. Science 2002; 296: 747-749. 
11 Agusti AGN, Noguera A, Sauleda J, Sala E, Pons J, Busquets $X$. Systemic effects of chronic obstructive pulmonary disease. Eur Respir J 2003; 21: 347-360.

12 Amadori A, Zamarchi R, De Silvestro G, et al. Genetic control of the CD4/CD8 T-cell ratio in humans. Nat Med 1995; 1: 1279-1283.

13 Costabel U, Maier K, Teschler H, Wang YM. Local immune components in chronic obstructive pulmonary disease. Respiration 1992; 59: 17-19.

14 American Thoracic Society Official Statement. Standardization of Spirometry, 1994 Update. Am J Respir Crit Care Med 1995; 152: 1107-1136.

15 Roca J, Sanchis J, Agustí-Vidal A, Segarra F, Navajas D, Rodríguez-Roisin R. Spirometric reference values for a mediterranean population. Bull Eur Physiopathol Respir 1986; 22: 217-224.

16 Saetta M, Turato G, Maestrelli P, Mapp CE, Fabbri LM. Cellular and structural bases of chronic obstructive pulmonary disease. Am J Respir Crit Care Med 2001; 163 : 1304-1309.

17 De Jong JW, Belt-Gritter B, Koeter GH, Postma DS. Peripheral blood lymphocyte cell subsets in subjects with chronic obstructive pulmonary disease: association with smoking, IgE and lung function. Respir Med 1997; 91: 67-76.

18 Kim WD, Kim WS, Koh Y, et al. Abnormal peripheral blood T-lymphocyte subsets in a subgroup of patients with COPD. Chest 2002; 122: 437-444.

19 Rennard SI. Inflammation and repair processes in chronic obstructive pulmonary disease. Am J Respir Crit Care Med 1999; 160: Suppl. 5, S12-S16.

20 Richmond I, Pritchard GE, Aschcroft T, Corris PA, Walters EH. Distribution of gamma delta T-cells in the bronchial tree of smokers and non-smokers. I Clin Pathol 1993; 46: 926-930.

21 Majo J, Ghezzo H, Cosio MG. Lymphocyte population and apoptosis in the lungs of smokers and their relation to emphysema. Eur Respir J 2001; 17: 946-953.

22 Ekberg-Jansson A, Andersson B, Avra E, Nilsson O, Lofdahl CG. The expression of lymphocyte surface antigens in bronchial biopsies, bronchoalveolar lavage cells and blood cells in healthy smoking and never-smoking men, 60 years old. Respir Med 2000; 94: 264-272.

23 Chen Y, Chou K, Fuchs E, Havran WL, Boismenu R. Protection of the intestinal mucosa by intraepithelial gamma delta T cells. Proc Natl Acad Sci USA 2002; 99: 14338-14343.

24 King DP, Hyde DM, Jackson KA, et al. Cutting edge: protective response to pulmonary injury requires gamma delta T lymphocytes. J Immunol 1999; 162: 50335036.

25 Lahn M, Kanehiro A, Takeda K, et al. Negative regulation of airway responsiveness that is dependent on gammadelta T cells and independent of alphabeta T cells. Nat Med 1999; 5: 1150-1156.

26 Born WK, Lahn M, Takeda K, Kanehiro A, O’Brien RL, Gelfand EW. Role of gammadelta $\mathrm{T}$ cells in protecting normal airway function. Respir Res 2000; 1: 151-158.

27 Colonna-Romano G, Potestio M, Aquino A, Candore G, Lio D, Caruso C. Gamma/delta T lymphocytes are affected in the elderly. Exp Gerontol 2002; 37: 205-211.

28 Schauer U, Dippel E, Gieler U, et al. T cell receptor gamma delta bearing cells are decreased in the peripheral blood of patients with atopic diseases. Clin Exp Immunol 1991; 86: 440-443. 